\title{
Transgelin gene is frequently downregulated by promoter DNA hypermethylation in breast cancer
}

\author{
Nilufer Sayar', Gurbet Karahan ${ }^{1}$, Ozlen Konu', Betul Bozkurt², Onder Bozdogan³ and Isik G. Yulug ${ }^{1 *}$
}

\begin{abstract}
Background: $\mathrm{CpG}$ hypermethylation in gene promoters is a frequent mechanism of tumor suppressor gene silencing in various types of cancers. It usually occurs at early steps of cancer progression and can be detected easily, giving rise to development of promising biomarkers for both detection and progression of cancer, including breast cancer. 5-aza-2'-deoxycytidine (AZA) is a DNA demethylating and anti-cancer agent resulting in induction of genes suppressed via DNA hypermethylation.

Results: Using microarray expression profiling of AZA- or DMSO-treated breast cancer and non-tumorigenic breast (NTB) cells, we identified for the first time TAGLN gene as a target of DNA hypermethylation in breast cancer. TAGLN expression was significantly and frequently downregulated via promoter DNA hypermethylation in breast cancer cells compared to NTB cells, and also in 13/21 (61.9\%) of breast tumors compared to matched normal tissues. Analyses of public microarray methylation data showed that TAGLN was also hypermethylated in $63.02 \%$ of tumors compared to normal tissues; relapse-free survival of patients was worse with higher TAGLN methylation; and methylation levels could discriminate between tumors and healthy tissues with $83.14 \%$ sensitivity and $100 \%$ specificity. Additionally, qRT-PCR and immunohistochemistry experiments showed that TAGLN expression was significantly downregulated in two more independent sets of breast tumors compared to normal tissues and was lower in tumors with poor prognosis. Colony formation was increased in TAGLN silenced NTB cells, while decreased in overexpressing BC cells.
\end{abstract}

Conclusions: TAGLN gene is frequently downregulated by DNA hypermethylation, and TAGLN promoter methylation profiles could serve as a future diagnostic biomarker, with possible clinical impact regarding the prognosis in breast cancer.

Keywords: DNA methylation, Hypermethylation, Breast cancer, TAGLN, SM22 alpha, Prognosis, Diagnosis

\section{Background}

Breast cancer is the most common cancer in women, constituting $29 \%$ of new cancer cases estimated for 2015 in US. Breast cancer can be classified according to molecular and histological subtypes with the most aggressive behavior usually being attributed to the triple negative (TN) subtypes, characterized with loss of estrogen, progesterone, and Her2 receptor expressions [1-3].

Epigenetic changes are heritable changes in gene expression patterns that do not involve alterations in the nucleotide sequence of DNA [4]. DNA methylation is a well-known mechanism for epigenetic gene silencing in mammals. $\mathrm{CpG}$ islands are $\mathrm{CpG}$-rich regions around the

\footnotetext{
* Correspondence: yulug@fen.bilkent.edu.tr

'Department of Molecular Biology and Genetics, Bilkent University, Faculty of Science, TR-06800 Ankara, Turkey

Full list of author information is available at the end of the article
}

promoters; 5' untranslated regions and first exons of many genes and are usually unmethylated in normal cells [5]. The methylated state of a CpG island usually refers to transcriptionally repressed promoters [5]. Tumor suppressor genes (TSG) may become inactivated during tumorigenesis through hypermethylation of associated $\mathrm{CpG}$ islands, providing several survival advantages [5-8].

5-aza-2'-deoxycytidine (Decitabine, AZA), a cytosine analogue that causes covalent arrest of DNA methyltransferases (DNMT) upon binding, is one of the most commonly used DNMT inhibitors in cultured cells and to treat cancer patients $[9,10]$. Use of demethylating agents together with expression microarrays enables the analysis of genes that may be regulated by hypermethylation of their promoter regions [11]. Discovering these genes is essential not only for therapeutic achievements but can also serve diagnostic, prognostic, and monitoring purposes [12]. 
Detection of hypermethylated DNA as cancer biomarkers is advantageous regarding the stable nature of DNA, ease of detection, and specificity of DNA hypermethylation for tumor cells [13]. Many known cancer-related genes like RASSF1A, APC, BRCA1, GSTP1, and DAPK1 can be detected from serum or blood of breast cancer patients $[14,15]$. Yet, there is still demand for novel diagnosis markers for detection of early breast cancer. In this study, we utilized microarray expression profiling of AZA-treated breast cancer (BC) and non-tumorigenic breast (NTB) cell lines, and identified TAGLN gene to be a frequently hypermethylated gene and a potential future biomarker in breast cancer.

Transgelin (TAGLN, SM22 $\alpha$ ) is an actin-binding protein that is abundantly expressed in smooth muscle cells (SMC) [16-19]. It is downregulated in transformed fibroblasts and several cancer cell lines and tissues [20-24]. TAGLN gene function has been associated with increased senescence in fibroblasts [25-27], and with increased apoptosis in glomerular epithelial cells and prostate cancer cells [28, 29]. TAGLN suppresses MMP9 [30], a known element of invasion [31], and therefore prevents the migration of colon and prostate cancer cells [32]. Controversially, it has also been found to be increased in gastric cancer and in lymph node (LN) metastasis of colon cancer [33, 34].

Here, we show that TAGLN is an epigenetically suppressed candidate epigenetic biomarker for diagnosis in breast cancer, by presenting its consistent downregulation of expression and frequent hypermethylation in breast carcinoma cell lines as well as in three independent breast tumor tissue cohorts. We also provide evidence that TAGLN decreases the proliferation potentials of BC and NTB cells. Better survival of breast cancer patients with higher expression or lower promoter methylation of TAGLN, in addition to competence of its promoter methylation levels to discriminate cancer from healthy tissue, emphasize a possible clinical impact for this gene in breast cancer.

\section{Results}

\section{Changes in the transcriptome of breast cell lines upon AZA treatment}

We treated the MCF7 and MDA-MB-231 BC cells and a NTB cell line MCF12A with AZA or corresponding DMSO controls before subjecting them to microarray analysis to identify new TSG targets for promoter DNA hypermethylation in breast cancer. Quality control analyses proved our data to be of high quality, and replicates of each experiment correlated well with each other (data not shown). Expressions of large groups of genes were altered upon AZA treatment by 1.5 -fold and above, even at very stringent significance thresholds (Additional file 1 and Additional file 4: Table S1). A selection procedure was applied to identify the genes that are altered upon AZA treatment in MCF7 and MDA-MB-231 cells, but not in MCF 12A cells (Additional file 2 and Fig. 1a). Gene lists, generated using this procedure, were used for further analyses (Additional file 3). Probe sets commonly or differentially altered in MCF7 and MDAMB-231 cell lines were also determined (Fig. 1b). We found that 17 and $22 \%$ of the probe sets induced in MCF7 or MDA-MB-231 cells, respectively, were induced in common while the remaining genes were cell-line specific.

Functional annotation and clustering of significantly altered genes in either the MCF7 or MDA-MB-231 cell lines were analyzed using the DAVID Functional Analysis Tool (Fig. 1c, d) [35, 36]. Pathways mainly involved in mitosis and cell cycle were significantly enriched among the downregulated genes in both of the cell lines. Pathways related to cell communication and motility, signal transduction, cell proliferation, and apoptosis regulation were significantly enriched among the AZAinduced genes in MCF7 (Fig. 1c) while regulation of gene expression was highlighted in addition to these pathways in MDA-MB-231 cells (Fig. 1d).

Paired $t$ tests between seven AZA-treated and untreated BC cell lines of a publicly available independent dataset (GSE20713 [37]) revealed that $53.5 \%$ of the probe sets that were significantly upregulated upon AZA treatment in both MCF7 and MDA-MB-231 cells in our experimental setup were also significantly upregulated in the AZA-treated BC cell lines of this independent study $(P<0.05$, Additional file 4: Table S2).

Probe set lists were screened for the presence of CpG islands in the proximity of their promoter regions, and the induction in expression levels of several genes were validated by qRT-PCR among the genes with proximal CpG islands. TAGLN emerged as a strong candidate gene among a large number of genes, as it was commonly and significantly upregulated upon AZA treatment in both MCF7 (by 27.3-fold) and MDA-MB-231 (by 1.77-fold) cell lines (Additional file 3), and our bioinformatics analyses showed that TAGLN expression was significantly downregulated $(>2$-fold, $P<0.05)$ in breast tumor tissues of 8 out of $13(62 \%)$ breast cancer datasets included in Oncomine database [38] (Additional file 4: Table S3). Moreover, TAGLN promoter region was previously shown to be responsive to hypermethylation in smooth muscle cells [39]. Based on these findings, we selected this gene for further analyses.

\section{TAGLN gene expression and promoter methylation analyses in breast carcinoma cell lines}

TAGLN gene expression was analyzed with qRT-PCR and found to be significantly downregulated in 15 different breast carcinoma cell lines compared to the nontumorigenic cell lines $(P=0.0034$, Fig. 2a). The expression 


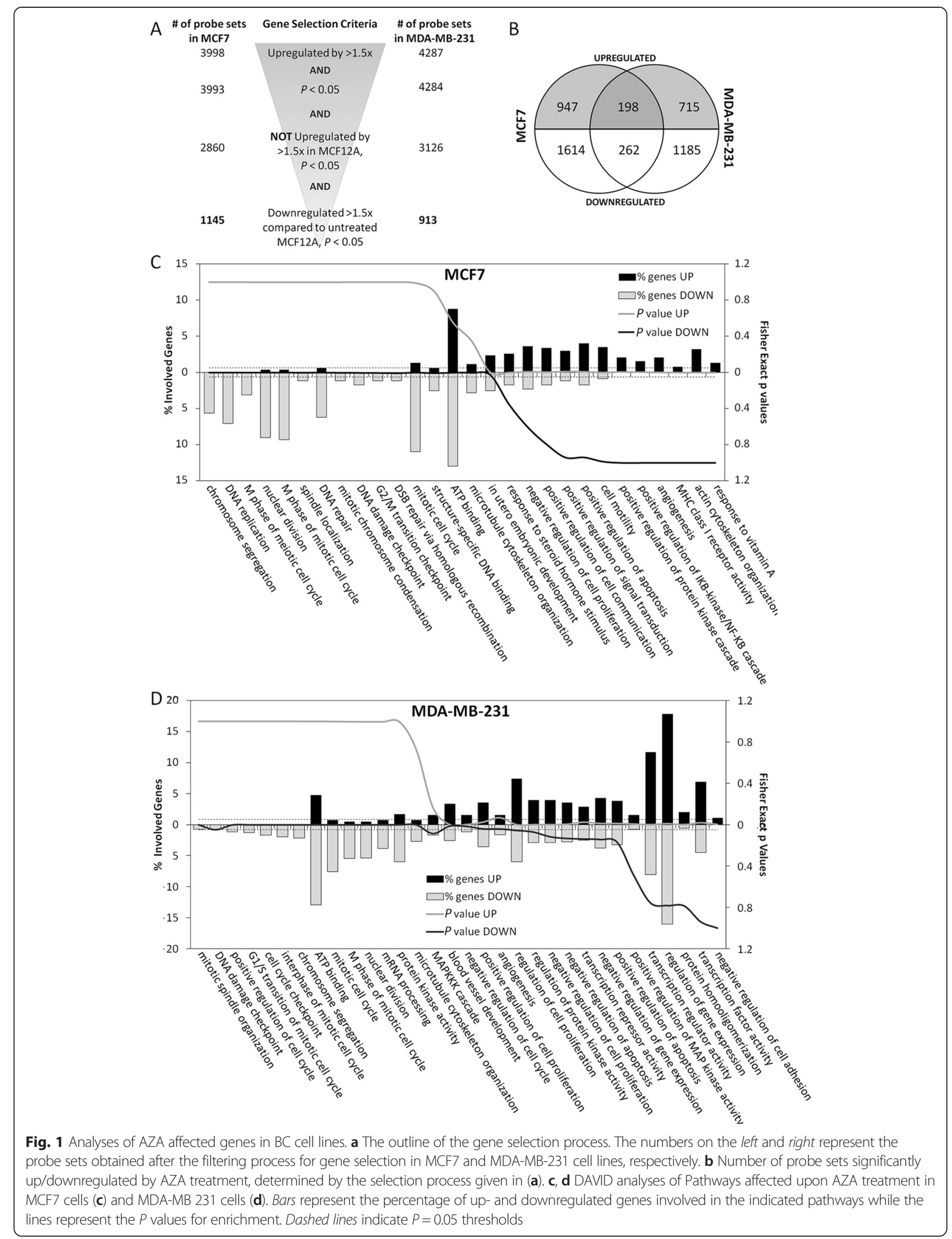




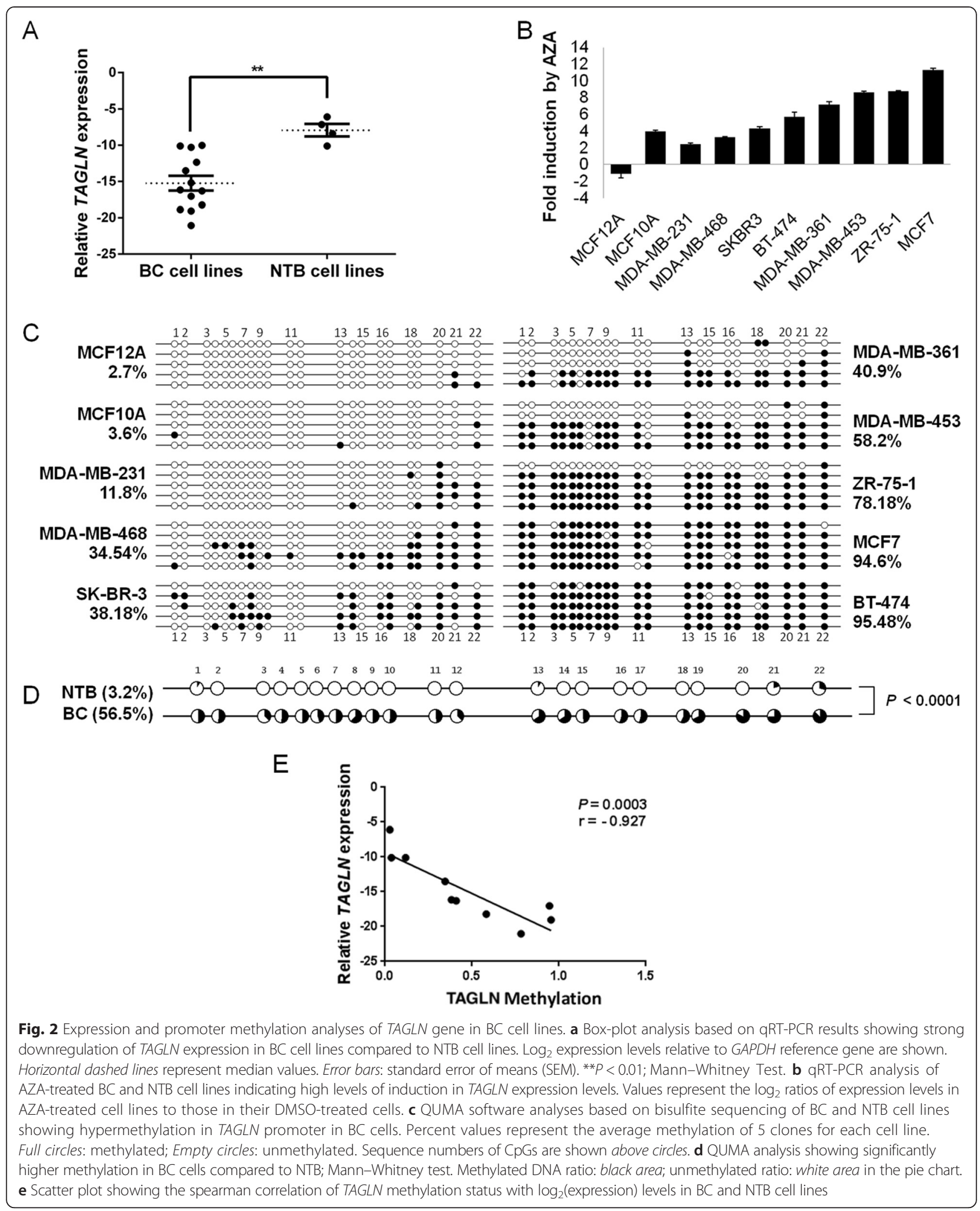

of TAGLN was restored in all analyzed cell lines upon AZA treatment, except for NTB cell line MCF12A (Fig. 2b). Expression levels of TAGLN were concordant in microarray and qRT-PCR experiments, when fold induction levels upon AZA treatment were compared in MCF7, MDA-MB-231, and MCF12A cell lines. 
Bisulfite sequencing of TAGLN promoter region was used to characterize TAGLN methylation status in eight $\mathrm{BC}$ and two NTB cell lines (Fig. 2c). The analyzed promoter region was significantly hypermethylated in majority of BC cell lines (with an average of $56.5 \%$ methylation) compared to the NTB cell lines (with an average of $3.2 \%$ methylation; $P<0.0001$, Fig. $2 d$ ). Moreover, mRNA expression and methylation levels of TAGLN were significantly and negatively correlated (Spearman $r=-0.927, P=0.0003$, Fig. 2e) suggesting that the expression of TAGLN was downregulated by promoter DNA methylation in $\mathrm{BC}$ cell lines.

TAGLN is downregulated by promoter hypermethylation in human breast tumor tissues

To profile the expression and methylation status of TAGLN in breast tumor tissues, TAGLN mRNA expression and promoter methylation levels were determined in 21 breast tumor samples and their pair-matched normal tissues (Table 1). The expression of TAGLN was found to be significantly downregulated in tumors compared to matched normal breast tissues by qRT-PCR

Table 1 Pathological features of normal matched breast tumor tissues

\begin{tabular}{lllllll}
\hline Patient code & Lymph node & Grade & Stage & $\begin{array}{l}\text { ER } \\
\text { status }\end{array}$ & $\begin{array}{l}\text { PR } \\
\text { status }\end{array}$ & Her2 \\
status
\end{tabular}

$E R$ estrogen receptor, $P R$ progesterone receptor, Her2 Erbb2 receptor amplification, N/A information regarding the pathological feature is missing, 1 positive for the given condition, 0 negative for the given condition
(19/21 tumors, $90.5 \%, P<0.0001$, Fig. 3a). The average relative expression (ARE) \pm standard error of means (SEM) was $0.476 \pm 0.1520$ for normal tissues while it was $0.146 \pm 0.0511$ for tumor tissues, with an average decrease in TAGLN expression of 3.255 -fold in breast tumor tissues.

The promoter methylation status of TAGLN was analyzed via the bisulfite sequencing method, and the examined region was found to be significantly hypermethylated in $13(61.9 \%)$ tumors $(P<0.05$, Fig. 3b, Table 2$)$ compared to matched normal tissues; hypermethylation was consistent across all grades (Table 2). The overall methylation levels were also significantly higher in tumor tissues in comparison with normals $(P=0.0263$, Fig. 3c). TAGLN mRNA expression and the promoter methylation ratios were significantly and negatively correlated in breast tissues (Spearman $r=-0.31, P=0.044$, Fig. $3 \mathrm{~d}$ ) as in BC cell lines, suggesting that TAGLN transcription could be regulated by DNA methylation. We used ANLN (Anillin) gene expression, a poor prognosis and high cellular proliferation marker in breast cancer patients [40], to better infer proliferative capacity and prognostic status of the tumors. Expression of TAGLN was negatively (Spearman $r=-0.44, P=0.0039)$ and the promoter methylation of TAGLN was positively (Spearman $r=0.48, P=0.0011$ ) correlated with mRNA expression of $A N L N$ gene (Fig. 3e, f). This shows that TAGLN is likely to be downregulated more by promoter DNA hypermethylation in breast tumors with worse prognosis. When the tumors' pathological features were analyzed, promoter methylation, but not expression, of TAGLN was significantly decreased in LN negative tumors when compared with LN positives $(P=0.0476$, Additional file 5: Figure S1A-B) while both expression and methylation levels did not exhibit any significant difference between grades, stages, and hormone statuses in our tumor-normal matched breast tissue panel.

To increase our sample size and extend our DNA methylation analyses to a larger panel with clinical and long-term outcome data, we downloaded the publicly available methylation data of two independent microarray datasets (Super-series: GSE201713 [37], $n=247$ and GSE31979 [41], $n=124$ ), whose distributions for methylation scores were similar, and used the normalized average methylation scores (NAMS) of two probes corresponding to TAGLN gene. In support of our results, TAGLN probes were significantly hypermethylated in breast tumors (NAMS $\pm \mathrm{SEM}=72.88 \pm 0.9137$, $n=338)$ compared to normal tissues (NAMS $\pm \mathrm{SEM}=$ $42.49 \pm 1.541, n=33, P<0.0001$, Fig. 4a), even though the $\mathrm{CpG}$ dinucleotides corresponding to the probes were not covered by our bisulfite primers. $83 \%$ of the tumors displayed higher methylation scores than the highest score observed in the normal cohort. The average 


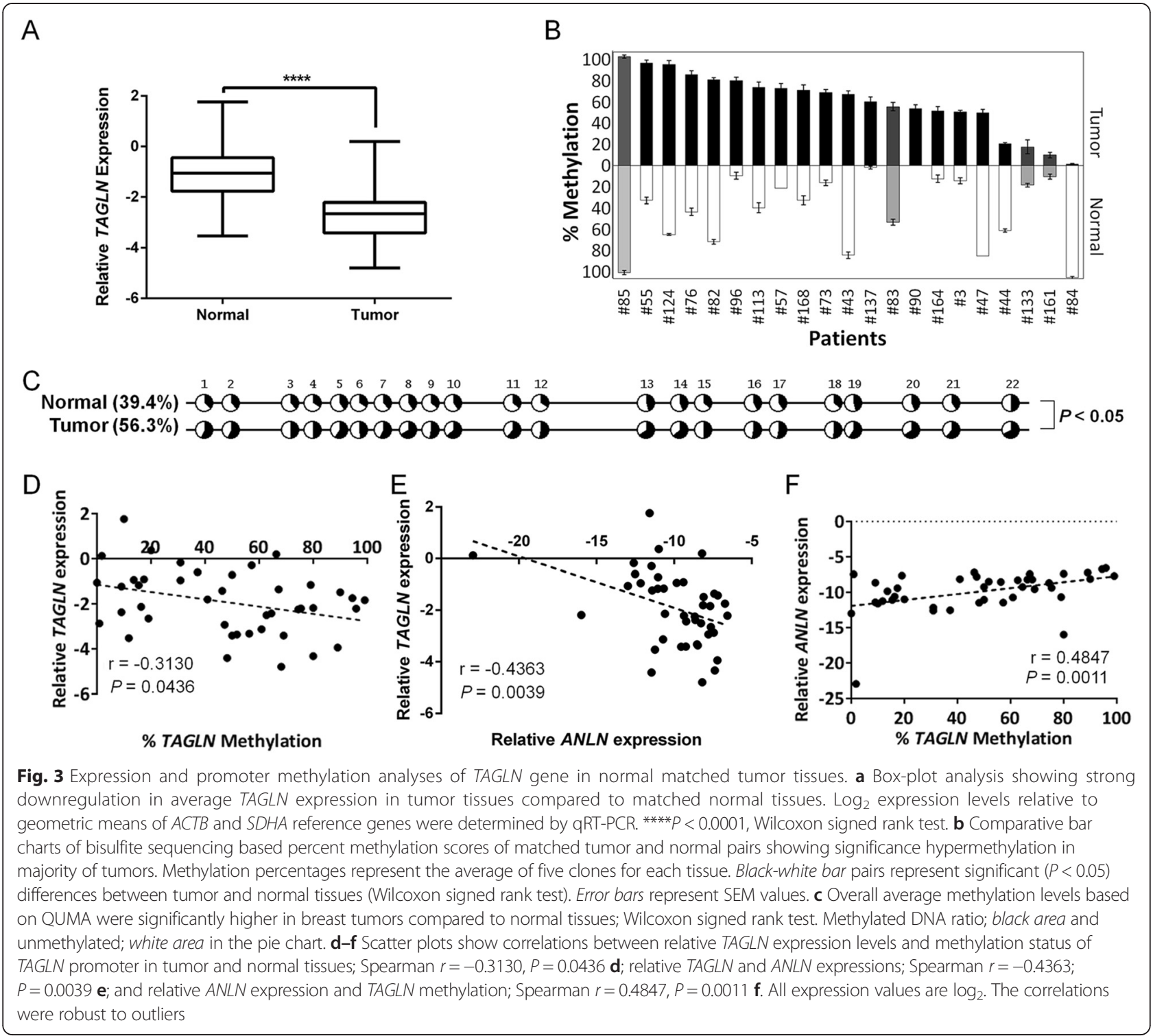

Table 2 Frequency of TAGLN hypermethylation in tumor and normal breast tissues

\begin{tabular}{|c|c|c|c|c|}
\hline$\underline{\text { Study }}$ & Analyzed CpGs & Cohort & Hypermethylated $^{c}$ & Hypomethylated $^{d}$ \\
\hline \multirow[t]{4}{*}{ Matched tumor tissue panel (bisulfite sequencing) $^{a}$} & -290 to +117 & All patients $(n=21)$ & $13(61.90 \%)$ & $4(19.05 \%)$ \\
\hline & 22 CpGs & Grade $1(n=5)$ & $5(100.00 \%)$ & $0(0.00 \%)$ \\
\hline & & Grade $2(n=11)$ & $6(54.55 \%)$ & $3(27.27 \%)$ \\
\hline & & Grade $3(n=2)$ & $1(50.00 \%)$ & $1(50.00 \%)$ \\
\hline \multirow[t]{4}{*}{ GSE20713 Methylation data (microarray analysis) ${ }^{b}$} & -571 and 455 & All patients $(n=338)$ & $213(63.02 \%)$ & $3(0.89 \%)$ \\
\hline & 2 CpGs & Grade $1(n=64)$ & $41(64.06 \%)$ & $0(0.00 \%)$ \\
\hline & & Grade $2(n=57)$ & $35(61.40 \%)$ & $1(1.75 \%)$ \\
\hline & & Grade $3(n=215)$ & 135 (62.79 \%) & $2(0.01 \%)$ \\
\hline
\end{tabular}

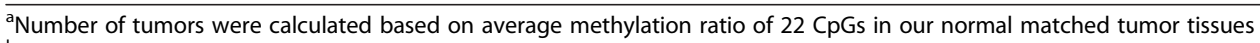

${ }^{b}$ Number of tumors were calculated based on average methylation scores of two probes corresponding to two CpGs at given locations

${ }^{c}$ Number of tumors that are significantly hypermethylated in normal matched tumor tissue panel $(P<0.05$, Wilcoxon signed rank test). In microarray methylation

data, tumors with normalized average methylation score (NAMS) $>30$ higher than the average normal tissue NAMS were considered hypermethylated

${ }^{\mathrm{d}}$ Number of tumors that are significantly hypomethylated in normal matched tumor tissue panel $(P<0.05$, Wilcoxon signed rank test). In microarray methylation

data, tumors with NAMS $>30$ lower than the average normal tissue NAMS were considered hypomethylated 
difference between the methylation scores of the tumor and normal tissues was 30.38; thus, the tumors with methylation scores that were $>30$ higher than the average value for normal tissues were considered as hypermethylated. Accordingly, $63.02 \%$ of the tumors displayed hypermethylation of TAGLN probes in this data set (Table 2). When grouped into tumor grades, these ratios were at least $61.40 \%$ for each group (Table 2). Available expression data (GSE20711; $n=90$ ) of the same patients were significantly and negatively correlated with TAGLN methylation scores (Spearman $r=-0.5442, P<0.0001$, Fig. $4 \mathrm{~b})$. This correlation was preserved in each grade and pathological subtype tested except for Luminal B (LumB) tumors, which are known for their hypermethylator phenotypes [42] (data not shown). Receiver-operator characteristics (ROC) analyses of TAGLN promoter methylation showed that a threshold of NAMS $>60.94$, which was derived from the ROC analysis itself, could discriminate healthy individuals from breast cancer patients, with $83.14 \%$ sensitivity and $100 \%$ specificity (area under the curve $(\mathrm{AUC})=0.9289$, and $95 \%$ confidence interval (CI): 0.9027 to 0.9552, $P<0.0001$, Fig. 4c). Moreover, 10-year relapse-free survival (RFS) of patients was significantly decreased with higher tumor methylation of the TAGLN probes compared to the patients with lower levels of methylation
$(P=0.0059$, Fig. $4 d)$. NAMSs of the TAGLN probes were compared for different pathological features of breast cancer, and TAGLN methylation states were similar, independent of grade, Her2, and ER states, and sizes of the tumors.

TAGLN mRNA and protein is downregulated in independent sets of breast tumor tissues

To confirm downregulation of TAGLN in both protein and mRNA levels in other independent breast tumor tissue panels of larger sample sizes with pathological information, expression of TAGLN was examined in a breast cancer tissue array by IHC staining (BioChain, Cat.No:Z7020005), and in an independent cDNA panel by qRT-PCR (OriGene, Cat.No:BCRT101). Both protein $(P=0.0116)$ and mRNA expression levels $(P=0.0072)$ of TAGLN were significantly downregulated in breast tumors in comparison to non-tumor tissues (Fig. 5a, b). Average of relative mRNA expression, $\mathrm{ARE}_{(\mathrm{mRNA})} \pm \mathrm{SEM}$ was $0.4248 \pm 0.0792$ in normal tissues $(n=7)$ and $0.1858 \pm 0.0387$ in tumor tissues $(n=41)$. Average histochemical score $\mathrm{H}$-score \pm SEM was $243.6 \pm 25.35$ in normal tissues $(n=7)$, with extensive staining in myoepithelial cells (Fig. 5a), and was $169.8 \pm$ 9.773 in tumor tissues $(n=67)$. In both the tissue and cDNA arrays, TAGLN expression was downregulated in grade 3 tumors when compared to grade 1 and 2 tumors

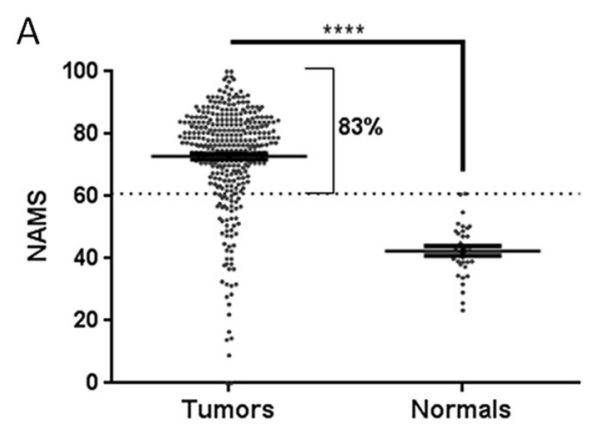

C

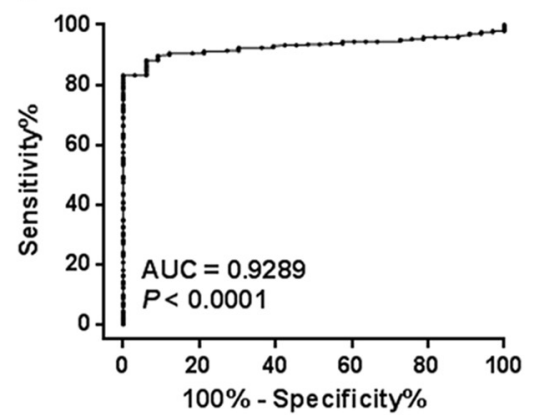

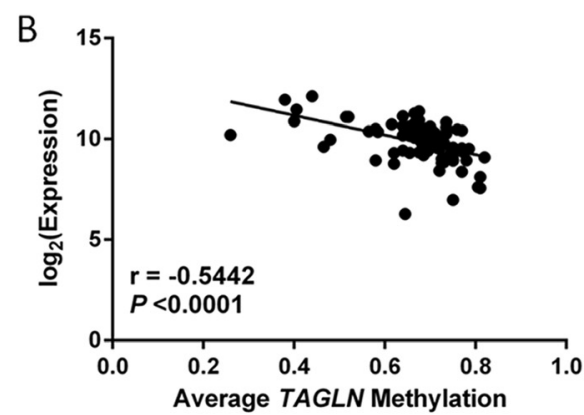

D

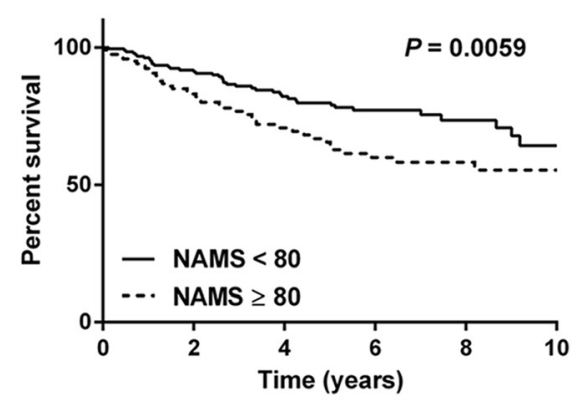

Fig. 4 Methylation status of TAGLN in public datasets GSE20713 and GSE31979. a Graphs showing higher normalized average methylation scores (NAMS) for two probes of TAGLN in tumor tissues Mann-Whitney test, ${ }^{* * * *} P<0.0001$. Horizontal lines: mean \pm SEM. $\mathbf{b}$ Scatter plot showing correlation of average methylation scores of TAGLN probes (GSE20713) to average expression ( $\left.\log _{2}\right)$ of TAGLN probe sets (GSE20711); Spearman $r=-0.5442, P<0.0001$. c ROC analyses for discrimination between healthy individuals and breast cancer patients, using TAGLN NAMSs. d Kaplan-Meier (KM) survival analysis showing higher RFS percentages for patients with tumor TAGLN NAMSs $\leq 80$ (best cutoff among tested) 


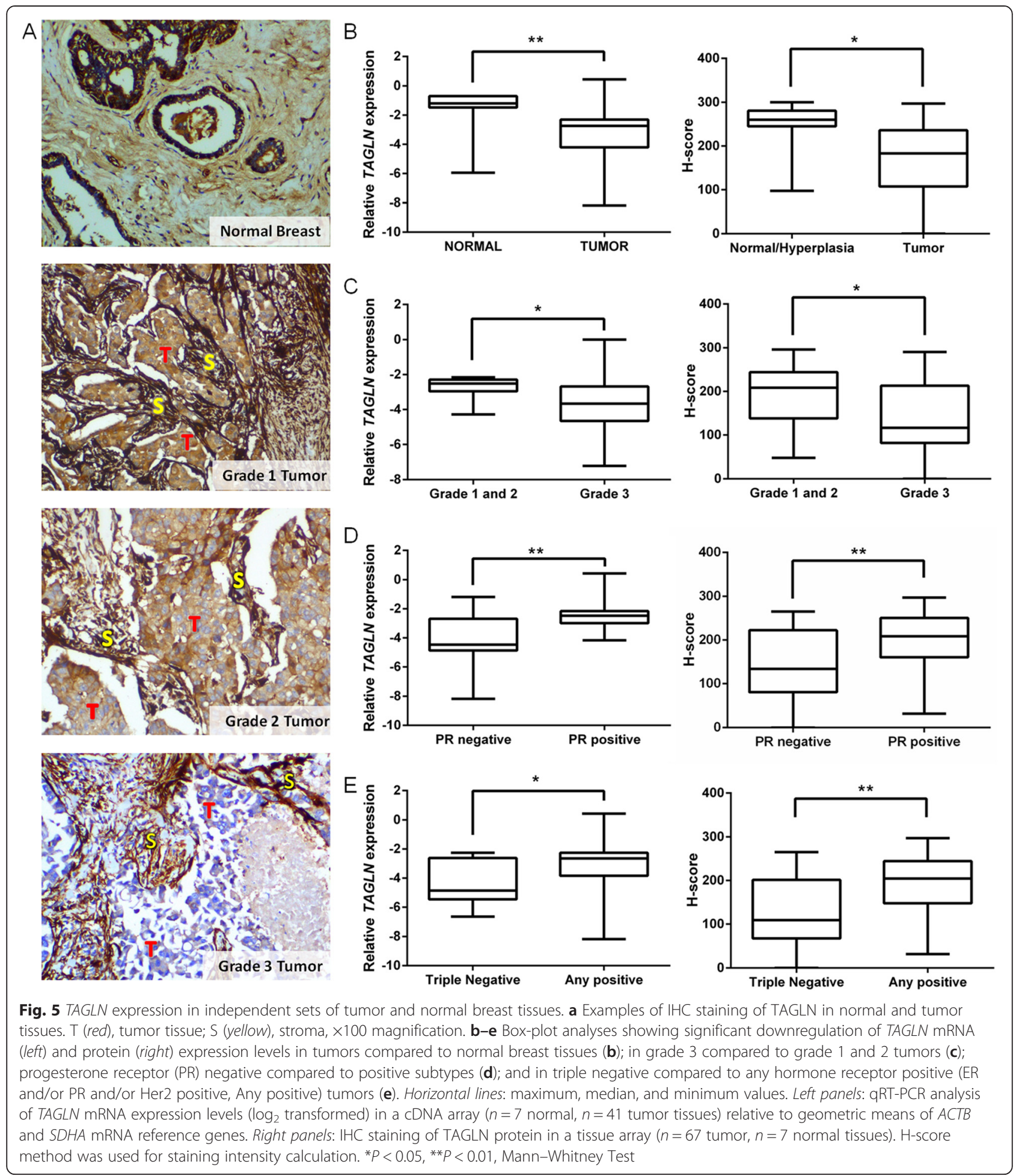

( $P=0.049$ and $P=0.0329$, respectively, Fig. $5 \mathrm{c})$, upregulated in progesterone receptor PR $(+)$ tumors $(P=0.0031$ and $P=0.0043$, respectively, Fig. $5 \mathrm{~d}$ ) and in any hormone receptor positive tumors with respect to triple negative tumor types $(P=0.0063$ and $P=0.0489$, respectively, Fig. 5e). TAGLN expression levels were not significantly different in estrogen receptor (ER) or human epidermal growth factor receptor 2 (Her2) positive or negative tumors or in different stage groups.

The tissue panels used in this study did not have enough information about patient survival data. KM plotter [43], which uses public microarray expression data for survival 
analyses, was used to test the effect of TAGLN expression on OS or RFS of breast cancer patients (Additional file 5: Figure S2). There was no significant difference between either OS or RFS of the patients based on their tumor expression levels of TAGLN when all patient cohorts were analyzed (Additional file 5: Figure S2A). However, when the patients were grouped for tumor grades, higher expression of TAGLN was associated with increased OS and RFS probabilities in patients with grade 1 and 2 tumors (Additional file 5: Figure S2B). In grade 3 tumors, the differences were not significant.

\section{TAGLN decreases colony formation potentials of breast carcinoma cell lines}

Since TAGLN was frequently hypermethylated and consistently downregulated in both the $\mathrm{BC}$ cell lines and three independent panels of tumor tissues, we analyzed the functional role of TAGLN in BC and NTB cells. TAGLN gene was silenced in MCF10A and MCF12A cells with abundant expression (Fig. $6 \mathrm{a}-\mathrm{C}$ ), and was overexpressed it in MDA-MB-361 and MDA-MB-157 BC cell lines (Fig. 6d, e) that expressed TAGLN at zero to intermediate levels, respectively (Fig. 6a). 2D colony formation assays were performed to test the effect of TAGLN on proliferation potentials of these cells. Compared to control siRNA (siCTRL), siTAGLN transfected MCF10A and MCF12A cells formed significantly ( $P=0.0013$ and $P=0.0016$, respectively) higher number of colonies (Fig. 6b, c, middle and lower panels). Colony formation capabilities of MDA-MB-361 cells, but not MDA-MB-157 cells, were significantly impaired when they overexpressed TAGLN protein (Fig. 6d, middle and lower panels and Fig. 6e, right panel). To examine possible effects of TAGLN on migration and invasion potentials of $\mathrm{BC}$ cells, we performed in vitro wound healing and Matrigel invasion assays in normally motile MDA-MB-157 cells; however, TAGLN overexpression in these cells did not affect either wound closure or Matrigel invasion capacities of these cells (Additional file 5: Figure S3).

\section{Discussion}

The combination of high-throughput expression profiling technology and treatment of cells with various DNA methylation inhibitors has been widely used to discover genome-wide effects of these drugs or to identify specific genes involved in the related pathways. Here, we used the same technology and identified TAGLN as an important candidate biomarker, frequently downregulated by promoter hypermethylation in breast cancer. A recent study (GEO ID: GSE22250) also used this method in breast cancer [37], in which multiple breast cancer cell lines without biological replicates were exposed to $1 \mu \mathrm{M}$ AZA. About half of the probe sets commonly upregulated in $\mathrm{BC}$ cells by AZA treatment in our setup were also upregulated $(P<0.05)$ in the AZA-treated BC cell lines in the aforementioned study, although they used a lower dose $(1 \mu \mathrm{M})$ of AZA. This indicates a potential dose dependency of AZA treatment such that some of the genes may require higher concentration of AZA to be induced. However, we determined TAGLN to be upregulated by 2.38-fold (average of two probe sets, $P<0.05$, paired $t$ test) also in GSE22250 study, yet this was not reported by the authors.

The pathway analyses of $5 \mu \mathrm{M}$ AZA-induced genes revealed that the most significantly enriched pathways in MCF7 cells were the cell motility, angiogenesis, cytoskeleton, and cell communication pathways, which could have been suppressed in these non-motile cells under normal conditions by DNA methylation. Yet, motilityassociated genes in invasive and motile MDA-MB-231 cells might have already been active even before the AZA treatment, so only gene expression and protein kinase regulation pathways were enriched upon AZA treatment. Commonly induced pathways in both cell lines were those relatively known as characteristics of the AZA effect on cancer cell lines [44-47], while commonly downregulated pathways mostly consisted of the cell cycle, cell division and metabolism-related pathways, potentially resulting in cessation of cell growth and proliferation when deactivated, enabling AZA's anti-cancer effect. Yet, most of these downregulated genes could be possibly repressed due to secondary effects of AZA treatment, as it caused induction of several transcription regulatory genes.

The promoter region of TAGLN, one of the strongest candidate genes among many probe sets, was previously found to be methylated in hepatocellular carcinoma and normal hepatocytes [48] and was hypermethylated in colorectal carcinoma [49]. Using a luciferase reporter gene construct containing the 5 '-flanking region of TAGLN promoter, and in vitro methylation of the CpG dinucleotides within this region, Yamamura et al. [39] showed that the transcriptional activity of TAGLN promoter could indeed be controlled by DNA methylation in smooth muscle cells. However, transcriptional regulation of this gene in breast cancer has never been studied before.

Our study is the first to document the regulation of TAGLN gene expression by promoter hypermethylation in both breast carcinoma cell lines and normal matched tumor breast tissues, as well as in tumor tissues of large set of publicly available data by means of bioinformatics analyses. Frequent hypermethylation of the TAGLN promoter region, in breast cancer even at low-grade tumors, is comparable to the hypermethylation frequencies of known TSGs in breast and other types of tumors [50]. High frequency of DNA hypermethylation of certain 


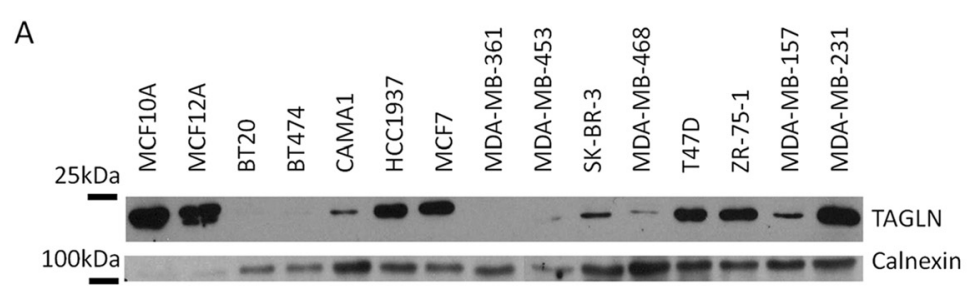

B
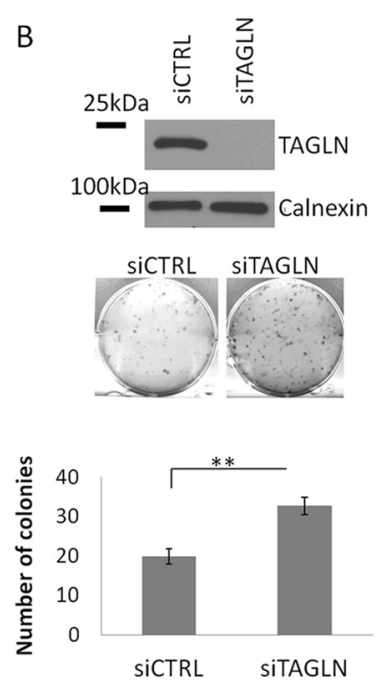

E

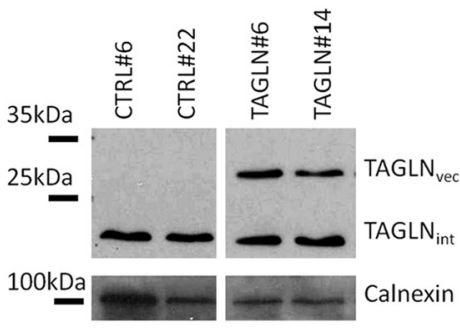

C
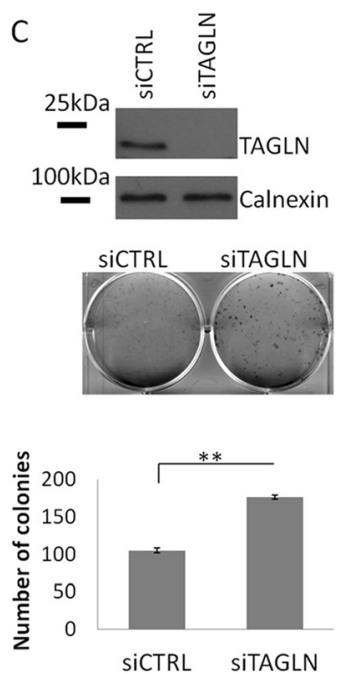

D
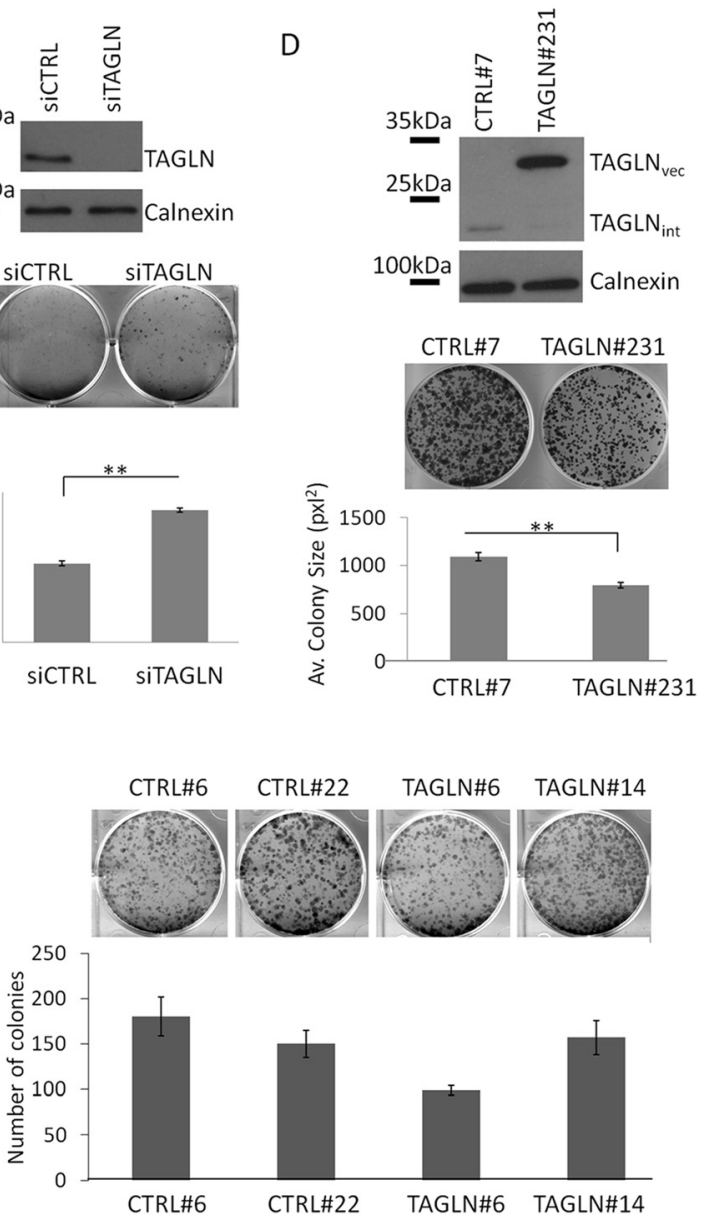

Fig. 6 Effect of TAGLN overexpression and silencing on breast cell lines. a Western blot analysis of TAGLN in breast carcinoma and non-tumorigenic breast cell lines. b-c Western blot shows TAGLN silencing in MCF10A (b) and MCF12A (c) cells (upper panels). 2D colony formation assays (middle and lower panels) show increased colony formation in TAGLN silenced (siTAGLM) MCF10A (b) and MCF12A (c) cells compared to controls (siCTRL). d-e Western blot analyses of TAGLN overexpression and subsequent colony formation assays in MDA-MB-361 (d, upper panel), and MDA-MB-157 (e, left panel) cell clones. Overexpression of ectopic TAGLN (TAGLN $N_{\text {vec }}$ and levels of endogenous TAGLN (TAGLN $\mathrm{N}_{\text {int) }}$ were determined with TAGLN specific antibody in clones. TAGLN overexpression caused higher cell proliferation in MDA-MB-361 cells (e), while did not affect MDA-MB-157 cells (f). Each assay was conducted at least in quadruplicates. Two sample $t$ test was used for comparisons. Error bars represent standard errors. ${ }^{* *} P<0.01$

genes enables detection of circulating cell-free tumor DNA from easily accessible and noninvasive sites, like serum or plasma, of cancer patients, with quick and sensitive techniques such as methylation-specific PCR (MSP) $[14,15,51]$. Even though it is possible to detect and analyze hypermethylated genes from the fine needle aspirates, nipple aspirates, and ductal lavage for breast cancer patients [52-54], diagnosis from serum or plasma is more patient friendly and noninvasive and can be easily repeated during the follow-up period. Thus, pursuit for blood-based tests for diagnosis of breast cancer has been an ever expanding research area $[12,55]$. The most common biomarker candidates for detection of breast cancer from serum is RASSF1A gene, with $100 \%$ specificity and $75 \%$ sensitivity [56], and RAR $\beta$ with $94 \%$ specificity and $87 \%$ sensitivity [57]. Based on the high frequency of hypermethylation in breast cancer patients compared to healthy tissues, TAGLN promoter methylation levels can be used as an epigenetic based biomarker for diagnosis, either alone or together with other frequent 
markers. Indeed, the results of our ROC analyses with high sensitivity and specificity values, point out TAGLN gene methylation as a good candidate for a tumor marker, with $83.14 \%$ sensitivity and $100 \%$ specificity. These ratios are similar to the ones obtained by combining the scores of more than one gene for detection of breast cancer (reviewed in Kristiansen 2013 [12]), and could increase their competence when included in these panels. The power of TAGLN promoter hypermethylation as an epigenetic diagnosis biomarker seems promising and should be validated for detection of tumor DNA from serum, plasma, or nipple and ductal fluids in a large, prospective screening study.

TAGLN methylation states also relate to the prognosis of breast cancer, as TAGLN promoter methylation levels were negatively correlated with cellular proliferation and worse prognosis marker ANLN expression in our tumornormal matched tissue panel [40]. Moreover, the probability of 10-year RFS of patients was greater with lower TAGLN methylation scores, independent of grade, stage, and other prognostic factors. These outcomes indicate that hypermethylation of TAGLN promoter can also be used as a prognostic marker. Larger cohorts of patients with matched breast cancer and adjacent normal tissues, and available survival information should be used to validate these findings with bisulfite sequencing or other sensitive techniques like MSP.

TAGLN expression was previously found to be downregulated in several types of cancer and transformed cells $[18,20-22,24]$. However, studies on breast cancer were limited to a small number of cell lines and tissues, all of which were ductal carcinoma in situ. In this study, we showed strong and consistent downregulation of TAGLN mRNA and protein expression in three independent sets of breast tumor tissues compared to nontumor tissues (total number of samples $n=130$ tumors and $n=35$ normal tissues). Furthermore, this is the first time an association between TAGLN expression and breast cancer prognosis is suggested by independent findings: (1) negative correlation of TAGLN expression with poor prognosis marker ANLN [40]; (2) decreased TAGLN expression particularly in triple negative breast cancer in addition to all molecular subtypes of breast cancer tissues; and (3) longer 10-year OS and RFS of low-grade breast cancer patients with higher TAGLN expression.

TAGLN is usually known as a mesenchymal protein [19], whose expression increases with epithelial to mesenchymal transition (EMT) [58-60]. In this study, we found that the expression of TAGLN was higher in grade 1 and 2 tumors compared to grade 3 , suggesting that TAGLN expression could be decreased even more when the tumor progresses into a more undifferentiated state in breast cancer. This suggests that downregulation of TAGLN expression may not be related to the EMT state of breast tumors while its downregulation can be an important marker in breast tumor progression. Future studies with higher numbers of grade 2 and grade 3 tumor samples will help increase confidence in this regard.

Previous data on association of TAGLN with metastatic states of other tumor types are also controversial. While some studies negatively correlated TAGLN expression with lymph node status in colon [32] and prostate cancers [61], others found positive correlation in colorectal cancer [34]. Increased expression of TAGLN in metastatic nerve sheath tumors was also shown [62]. At least part of the discrepancies in the expression levels of TAGLN in different studies has been explained as a result of higher TAGLN expression in the tumor stroma of invasive tumors rather than the tumor tissue itself, which is revealed by subsequent IHC staining analyses [33, 63-65]. Accordingly, extensive staining of TAGLN in the tumor stroma was also found in our panel of breast tissues stained by IHC, while TAGLN gene expression was specifically downregulated in tumor tissues of all grades and pathological types, when compared to normal tissues.

While some studies suggest a TSG function for TAGLN due to downregulation in different types of tumors $[22,24,32,49,60,66,67]$, others define tumorpromoting activities or overexpression in cancer [34, 68, 69]. Despite these contradictory functions suggested in different types of tumors, our findings support a possible tumor suppressive role of this protein in breast cancer. The observed anti-proliferative effect exerted by TAGLN on breast cells in our study can be caused by its close association with the actin cytoskeleton $[17,70]$, which has essential roles in several pathways in a cell (reviewed in Hall, 2009 [71]). TAGLN expression is known to directly affect actin cytoskeleton dynamics [60, 70, 72, 73]. In yeast, higher expression of TAGLN homolog Scp1 decreases actin dynamics, leading to increased permeability of mitochondria and release of reactive oxygen species (ROS), which in turn results in cell death [74]. Similar results have been reported in melanoma cells [75]. Likewise, TAGLN depletion in fibroblasts resulted in disrupted actin organization and lower levels of ROS [60]. Thus, lower TAGLN expression observed in breast tumors and cell lines can support tumor development or cell proliferation by means of decreased ROS production resulting in longevity, or other mechanisms and pathways involved, which should be further tested in a comprehensive and focused functional study.

TAGLN is known to be involved in SMC migration via formation of podosomes and focal adhesions [73, 76, 77], as well as in lung fibrosis [78]. Controversially, its overexpression results in decreased cellular migration in colon cancer $[32,79]$. We found that overexpression of TAGLN 
in MDA-MB-157 cells did not cause any significant change in both the migration and invasion capabilities of these BC cells. It is possible that TAGLN acts differently in mesenchymal SMCs and in epithelial origin of cancer cells, as protein profiles might differ among different cell types, affecting the functions of individual proteins. Further studies are required to unravel possible protein partners of TAGLN in cells with different origins to explain the contradictory outcomes observed in different studies.

\section{Conclusions}

Our novel findings support the essential role of TAGLN gene in breast cancer pathogenesis, regarding its negative effect on cellular proliferation and its consistent downregulation in tumors. Based on substantially high methylation frequencies in breast cancer, further studies focusing on TAGLN promoter methylation as a diagnostic marker, combined with other biomarkers, should seriously be considered. These further studies with expanded breast cancer patient cohorts and bisulfite sequencing accompanied with expression analyses will determine whether TAGLN expression and/or methylation could also be used as a prognostic marker as well.

\section{Methods}

Cell culture and AZA treatment of breast cell lines MCF7, MDA-MB-231, MDA-MB-453, MDA-MB-468, BT20, BT-474, ZR-75-1, HCC1937, MDA-MB-361, MDAMB-157, and MCF12A cell lines were purchased from American Type Culture Collection (ATCC). MCF10A cell line was kindly provided by Elif Erson Bensan, (METU, Ankara, Turkey). All cell lines were grown as recommended by ATCC. AZA ( $5 \mu \mathrm{M}$, Sigma-Aldrich, A3656) dissolved in DMSO (Applichem, A1584.0100) was used to treat cells for $96 \mathrm{~h}$, and equivalent amount of DMSO was used as control treatment. Media was changed at every 24th hour, and cells were harvested at $96^{\text {th }}$ hour.

\section{RNA isolation, determination of RNA quality and hybridization to microchips}

RNA was isolated from the cell lines with Nucleospin RNA kit (Macherey-Nagel (MN), 740955.5), quantified with NanoDrop ND-1000 spectrophotometer (Thermo Scientific, USA) and the RNA integrity was determined with Agilent 2100 Bioanalyzer (Agilent Technologies, Germany) and all RNA samples had RNA integrity number (RIN) between 9.8-10. Hybridization of the processed RNA samples to the gene chips (HGU-133-Plus 2.0, Affymetrix, USA) were done following the standard Affymetrix protocol, in the Microarray Hybridization Facility, at Bilkent University (Ankara, Turkey).

\section{Quality control and analysis of the microarray expression data}

Data were scanned from the microchips with GCOS software (Affymetrix, USA). Raw data were normalized with justRMA method using BRB-ArrayTools 3.8.0-beta, developed by Dr. Richard Simon and the BRB-ArrayTools Development Team (NCI, USA). Quality control and further analyses were performed using BrB-ArrayTools. RNA degradation plots and $3^{\prime}$ to $5^{\prime}$ signal ratios for probe sets corresponding to $A C T B$ and GAPDH mRNAs were calculated for quality control assessments. Class comparison tool, which uses random variance model of $t$ test for small size samples, was used to find differentially expressed genes between treatment groups. Functional annotations were done using "Functional Annotation Chart" tool of DAVID Bioinformatics Resources 6.7 (NIH, USA).

\section{CDNA synthesis and quantitative RT-PCR}

cDNA was synthesized from $1 \mu \mathrm{g}$ total RNA, using oligodT primers and RevertAid First Strand cDNA Synthesis Kit (Thermo Scientific, K1622) according to user's protocol. Specific primers for PCR amplification (available upon request) were designed using PrimerBlast of NCBI [80]. qRT-PCR experiments were performed in duplicates, using DyNAmo ${ }^{\text {Tx }}$ HS SYBR ${ }^{\bullet}$ Green qPCR Kit (Thermo Scientific, F-410 L). GAPDH as a reference gene was tested by calculating the significance of the $\log _{2}$ fold change of multiple probe sets represented in the array. Our results suggested that GAPDH was a reliable and stable reference gene in response to AZA treatment in MCF7, MDA-231, and MCF12A cell lines since no probe set exhibited fold change greater than 1.2 fold ( $\log _{2}$ fold change: -0.28 , FDR $>0.1)$. Thus, GAPDH was used as an internal control gene in cell lines, and $A C T B$ and SDHA geometric means were used [81] for internal control genes in tissue samples. Delta Ct method [82] was used for relative quantification of mRNAs, using the calculated efficiency values of each primer pair. Statistical significance of differences between groups was tested with Mann-Whitney test or Wilcoxon signed rank test (for paired data), using the $\log _{2}$ transformed expression values, using GraphPad Prism 6.0 (GraphPad Software Inc., USA).

\section{DNA isolation, bisulfite treatment and sequencing}

DNA was obtained using Nucleospin Tissue kit (MachereyNagel, 740952.5) as described in the user protocol. Bilsulfite treatment was carried out with $1 \mu \mathrm{g}$ DNA, using Epitect Bisulfite Kit (Qiagen, 59104). CpG islands were detected and bisulfite sequencing primers for TAGLN gene were designed using the Methyl Primer Express ${ }^{\circ}$ software (Applied Biosystems, USA). The primers amplified the region between -290 to +117 bp with respect to TSS (GenBank: NM_003186.3) (Left primer: 5'-GGGGTTAGAGAATAGTGAAGTAGGAGTA-3'; Right primer: 5'- 
ACACTCACAAAACTTCCTCAAAACT-3'). Gel extraction was carried out with the QIAquick Gel extraction kit (Qiagen, 28704). Specific PCR products were cloned into pGEM-T-easy cloning vector (Promega, A1360) after which plasmid isolation of selected colonies (5 for each sample) was performed with the PureLink Quick Plasmid Miniprep Kit (Invitrogen, K210011) and sent for sequencing. Sequencing of the bisulfite-treated DNA inserts was performed with SP6 primers using the dideoxy chain termination method (by Iontek, Istanbul, Turkey). Bisulfite sequencing results were analyzed using QUMA software [83]. Statistical differences between breast cancer and NTB cell lines were tested with Mann-Whitney test. Statistical differences between methylation percentages of paired tissues were tested with Wilcoxon signed rank test, in GraphPad Prism 6.0.

\section{Breast tumors and normal tissue samples}

TAGLN expression in publicly available datasets was analyzed using Oncomine ${ }^{\text {tw }}$ (Compendia Bioscience, USA). Primary breast tumors and their matched normal tissues (Table 1$)$ were surgically removed from patients $(n=21)$, at Numune Training and Research Hospital, Ankara, Turkey. The use of the tissue material in this project was approved by the Ethics Committee and consents were obtained in accordance with the Helsinki Declaration of 1975. Tumor samples used in the study were composed $>90 \%$ of tumor cells, according to hematoxylin and eosin staining. RNA isolation from tissues was performed with Trizol (Life Technologies, 15596-026). Breast tumor cDNA array (OriGene, BCRT101) was composed of 41 tumor and 7 normal tissues. Breast tumor tissue array (BioChain, Z7020005) was composed of 7 non-tumor and 68 tumor tissues of breast.

\section{IHC staining and scoring}

Immunohistochemical studies were performed automatically in the Bond Max equipment (Leica Microsystems Inc.). Antigen retrieval steps were performed in Bond-Epitope Retrieval Solution 1 (Leica Microsystems, Germany) with TAGLN antibody (1:500, Abcam ab1416) at $100{ }^{\circ} \mathrm{C}$. Detection was carried out with Bond Polymer Refine Red Detection kit (Leica Microsystems, DS9390). Stained slides were dehydrated and covered with mounting medium (Dako, CS70330) and cover-slips. Digital images of the slides were evaluated using the $\mathrm{H}$-score method [84]. Statistical differences between groups were calculated with Mann-Whitney test while correlations were tested with Spearman correlation, in GraphPad Prism 6.0.

\section{Survival analysis and analysis of publicly available methylation data}

Survival analyses regarding the expression of TAGLN were performed using Kaplan-Meier (KM) plotter, breast cancer cohort [43]. Gene expression information of 205547_s_at probe set corresponding to TAGLN was used. Auto cutoff was used to generate the best performing KM curves. To perform methylation analyses, all the methylation data published under super-series GSE20713 (GSE20712 and GSE22249) and a separate dataset (GSE31979), whose data distributions were similar, were downloaded from GEO2R. Both of the studies were performed on GPL8490 Illumina HumanMethylation27 BeadChip arrays. One probe (cg24619694) corresponded to a CpG at +445 position from TSS of TAGLN, and the other probe (cg06950730) corresponded to a CpG at -561 position. Methylation scores of two probes were correlated (Spearman coefficient $=0.714, P<0.0001$ ). Thus, average methylation scores of the two probes were used for the calculations. The data were normalized by assigning 0 for the lowest average methylation scores for two probes of TAGLN gene, and assigning the value 100 for the highest scores for each dataset, and the scores in between are fit into a sigmoidal curve. Normalized methylation scores (NAMS) were used for the further studies. MannWhitney test was used to compare two groups. For correlation analyses, expression data (GSE20711) corresponding to 88 breast cancer patients and 2 healthy individuals included in the methylation study (GSE20713) was downloaded from GEO2R, and the Spearman's rank correlation between expression and methylation scores was calculated. For survival analyses using the NAMS values, a range of values greater than or equal to the diagnostic cutoff (i.e., $60,65,70,75,80,85$, and 90) was tested, and the best performing cutoff was determined to be NAMS $>80$ [85]. Patients were divided into NAMS $\geq 80$ and NAMS $<80$ groups, and 10-year RFS were calculated for each group. $P$ values were calculated using Gehan-Breslow-Wilocoxon test in GraphPad Prism 6.0.

\section{Western blotting}

Protein lysates $(20-50 \mathrm{mg})$ from cell lines were separated under reducing conditions (5\% $\beta$-mercaptoethanol), in $12 \%$ Tris-glycine gels and SDS-Tris-glycine running buffer and were blotted on nitrocellulose membranes. Membranes were incubated overnight at $4{ }^{\circ} \mathrm{C}$, with primary antibodies $(\alpha$-TAGLN, Abcam ab1416, 1:2,000; $\alpha$-Calnexin, Abcam, 1:20,000), followed by washing with Tris buffered saline Tween-20 (0.25\%, TBS-T) and secondary antibody (horse radish peroxidase-conjugated anti-rabbit IgG, Abcam 1:5,000) incubations for $1 \mathrm{~h}$ at room temperature. Signal detection was performed with ECL prime system (Amersham Life Science, RPN2232).

\section{siRNA transfections and overexpression of TAGLN in breast} cancer cells

siGENOME Human TAGLN siRNA (SMARTpool, Thermo Scientific, M-003714-02-0020) and siGENOME 
Non-Targeting siRNA \#2 (Thermo Scientific, D-00121002-20) control siRNA transfections were performed with RNAi-max (Invitrogen, 13778150), using the reverse transcription protocol supplied by the producer. TAGLN overexpression, TrueORF-Gold pCMV6-Entry-TAGLN (Origene, RC215789), and control pCMV6-Entry vectors (Origene, PS100001) were transfected to MDA-MB-361 and MDA-MB-157 cells using Lipofectamine 2000 reagent (Invitrogen, 11668019). Stable clones were generated with Geneticin (Gibco-Life Technologies, 10131-035) selection.

\section{D colony formation assays}

Cells were seeded to be 2.000/well in 6-well plates and were grown for 2 weeks (MDA-MB-157, MCF10A, and MCF12A) or for 4 weeks (MDA-MB-361). Colonies were then stained with $0.5 \%$ crystal violet and counted using Image J (NIH). Colony sizes of MDA-MB-361 were calculated using Image J. Colony sizes of other cell lines could not be determined due to more scattered nature of colonies of these mesenchymal types of cells. Statistical differences were calculated with two sample $t$ test in GraphPad Prism 6.0.

\section{In vitro wound healing and Matrigel invasion assays}

For in vitro wound healing assays, cells were plated to be confluent in 24-well plates. Next day, media was changed to low serum media (0.5\% FBS) and at least 6 independent scratches/sample were made with $200-\mu$ l pipette tips, and photos were taken after $24 \mathrm{~h}$. Statistical differences between groups were tested with the Mann-Whitney test in GraphPad Prism 6.0. For Matrigel invasion assays, Growth Factor Reduced Matrigel Matrix Basement Membrane (BD, 356230) was diluted (1:5) and added to Transwell Permeable Support invasion chambers (Corning, 3422) in 24 wells to form a thin layer. Cells $(150,000)$ per chamber were added to the upper chamber with $0.5 \%$ serum containing media and the lower chamber was supplied with $10 \%$ serum containing medium. Cells on the lower side of the chamber were stained with Giemsa and counted at the $48^{\text {th }}$ hour.

\section{Availability of supporting data}

The data set supporting the results of this article is available in the Gene Expression Omnibus (GEO) repository, [GSE71363, http://www.ncbi.nlm.nih.gov/geo/query/acc. cgi?acc $=$ GSE71363].

\section{Additional files}

Additional file 1: Expression changes upon AZA treatments. Probe IDs, gene names, and fold change ratios of the genes altered upon AZA treatment in each cell line at 1.5 fold and $P<0.05$ have been listed. (XLSX 2886 kb)
Additional file 2: Expression in untreated breast cancer cell lines in comparison to MCF12A. Probe IDs, gene names, and relative expressions in breast cancer cell lines with respect to untreated MCF12A at 1.5 fold and $P<0.05$ have been listed. (XLSX $11397 \mathrm{~kb}$ )

Additional file 3: Final gene lists altered upon AZA treatments only in breast cancer cell lines. Probe IDs, gene names, accession numbers and fold change ratios of the genes altered upon AZA treatment, in each breast cancer cell line at 1.5 fold and $P<0.05$, and filtered as shown in Fig. 1A have been listed. (XLSX $387 \mathrm{~kb}$ )

Additional file 4: Tables not included in the main manuscript have been listed. Table S1. Number of probe sets affected by AZA treatment; Table S2. Comparison of significantly altered probe sets with the independent study GSE20713 Dataset; Table S3. Cancer vs. normal analysis of TAGLN mRNA in Oncomine database. (PDF 18 kb)

Additional file 5: Figure S1. TAGLN expression and methylation status, and lymph node metastasis of breast cancer; Figure S2. Univariate survival analysis of TAGLN microarray expression levels; Figure S3. Effect of TAGLN over-expression on migration and invasion of MDA-MB-157 cells. (PDF $1151 \mathrm{~kb}$ )

\section{Abbreviations}

ANLN: Anillin; ARE: average relative expression; AZA: 5-aza-2'-deoxycytidine, Decitabine; BC: breast carcinoma; DMSO: dimethyl sulfoxide; LN: lymph node; NAMS: normalized average methylation score; NTB: non-tumorigenic breast; ROC: receiver-operator characteristics; SEM: standard error of means; TAGLN: transgelin; TN: triple negative; TSG: tumor suppressor gene.

Competing interests

The authors declare that they have no competing interests.

\section{Authors' contributions}

NS performed laboratory experiments and statistical analyses at all steps, interpreted the results, and wrote and revised the manuscript. GK performed initial laboratory experiments and revised the manuscript. OK mentored statistical analyses and revised the manuscript. BB provided tissue samples, conducted pathology review and revised the manuscript. OB performed tissue array $\mathrm{IHC}$ experiments, conducted pathology review and revised the manuscript. IGY designed the approach, interpreted the results, and wrote and revised the manuscript. All authors have read and approved the final manuscript.

\section{Authors' information}

Not applicable

Availability of data and materials

Not applicable

\section{Acknowledgements}

This study has been supported by grants from The Scientific and Technological Research Council of Turkey (TÜBITAK-107T181). and Bilkent University.

\section{Author details}

'Department of Molecular Biology and Genetics, Bilkent University, Faculty of Science, TR-06800 Ankara, Turkey. ${ }^{2}$ Department of General Surgery, Ankara Numune Training and Research Hospital, 06100 Ankara, Turkey. ${ }^{3}$ Department of Pathology, Ankara Numune Training and Research Hospital, 06100 Ankara, Turkey.

Received: 26 July 2015 Accepted: 18 September 2015

Published online: 28 September 2015

\section{References}

1. Dent R, Trudeau M, Pritchard KI, Hanna WM, Kahn HK, Sawka CA, et al. Triplenegative breast cancer: clinical features and patterns of recurrence. Clin Cancer Res. 2007;13(15 Pt 1):4429-34. doi:10.1158/1078-0432.CCR-06-3045.

2. Perou CM, Sorlie T, Eisen MB, van de Rijn M, Jeffrey SS, Rees CA, et al. Molecular portraits of human breast tumours. Nature. 2000;406(6797):747-52. doi:10.1038/35021093. 
3. Sorlie T, Perou CM, Tibshirani R, Aas T, Geisler S, Johnsen H, et al. Gene expression patterns of breast carcinomas distinguish tumor subclasses with clinical implications. Proc Natl Acad Sci USA. 2001;98(19):10869-74. doi:10.1073/ pnas.191367098.

4. Herman JG, Baylin SB. Gene silencing in cancer in association with promoter hypermethylation. N Engl J Med. 2003;349(21):2042-54. doi:10.1056/ NEJMra023075.

5. Esteller M. Cancer epigenomics: DNA methylomes and histonemodification maps. Nat Rev Genet. 2007;8(4):286-98. doi:10.1038/ nrg2005.

6. Hanahan D, Weinberg RA. The hallmarks of cancer. Cell. 2000;100(1):57-70.

7. Baylin SB, Esteller M, Rountree MR, Bachman KE, Schuebel K, Herman JG. Aberrant patterns of DNA methylation, chromatin formation and gene expression in cancer. Hum Mol Genet. 2001;10(7):687-92.

8. Dworkin AM, Huang TH, Toland AE. Epigenetic alterations in the breast: implications for breast cancer detection, prognosis and treatment. Semin Cancer Biol. 2009;19(3):165-71. doi:10.1016/j.semcancer.2009.02.007.

9. Qiu X, Hother C, Ralfkiaer UM, Sogaard A, Lu Q, Workman CT, et al. Equitoxic doses of 5-azacytidine and 5-aza-2'deoxycytidine induce diverse immediate and overlapping heritable changes in the transcriptome. PLoS One. 2010;5:9. doi:10.1371/journal.pone.0012994.

10. Momparler RL, Cote S, Momparler LF, Idaghdour Y. Epigenetic therapy of acute myeloid leukemia using 5-aza-2'-deoxycytidine (decitabine) in combination with inhibitors of histone methylation and deacetylation. Clin Epigenetics. 2014;6(1):19. doi:10.1186/1868-7083-6-19.

11. Suzuki H, Gabrielson E, Chen W, Anbazhagan R, van Engeland M, Weijenberg MP, et al. A genomic screen for genes upregulated by demethylation and histone deacetylase inhibition in human colorectal cancer. Nat Genet. 2002;31(2):141-9. doi:10.1038/ng892.

12. Kristiansen $S$, Jorgensen $L M$, Guldberg P, Soletormos G. Aberrantly methylated DNA as a biomarker in breast cancer. Int J Biol Markers. 2013;28(2):141-50. doi:10.5301/jbm.5000009.

13. Mulero-Navarro S, Esteller M. Epigenetic biomarkers for human cancer: the time is now. Crit Rev Oncol Hematol. 2008;68(1):1-11. doi:10.1016/ j.critrevonc.2008.03.001.

14. Radpour R, Barekati Z, Kohler C, Lv Q, Burki N, Diesch C, et al. Hypermethylation of tumor suppressor genes involved in critical regulatory pathways for developing a blood-based test in breast cancer. PLoS One. 2011;6(1), e16080. doi:10.1371/journal.pone.0016080.

15. Laird PW. The power and the promise of DNA methylation markers. Nat Rev Cancer. 2003;3(4):253-66. doi:10.1038/nrc1045.

16. Prinjha RK, Shapland CE, Hsuan JJ, Totty NF, Mason IJ, Lawson D. Cloning and sequencing of cDNAs encoding the actin cross-linking protein transgelin defines a new family of actin-associated proteins. Cell Motil Cytoskeleton. 1994;28(3):243-55. doi:10.1002/cm.970280307.

17. Shapland C, Lowings P, Lawson D. Identification of new actin-associated polypeptides that are modified by viral transformation and changes in cell shape. J Cell Biol. 1988;107(1):153-61.

18. Camoretti-Mercado B, Forsythe SM, LeBeau MM, Espinosa 3rd R, Vieira JE, Halayko AJ, et al. Expression and cytogenetic localization of the human SM22 gene (TAGLN). Genomics. 1998:49(3):452-7. doi:10.1006/ geno.1998.5267.

19. Lees-Miller JP, Heeley DH, Smillie LB. An abundant and novel protein of $22 \mathrm{kDa}$ (SM22) is widely distributed in smooth muscles. Purification from bovine aorta. Biochem J. 1987;244(3):705-9.

20. Almendral JM, Santaren JF, Perera J, Zerial M, Bravo R. Expression, cloning and cDNA sequence of a fibroblast serum-regulated gene encoding a putative actin-associated protein (p27). Exp Cell Res. 1989;181(2):518-30.

21. Schenker T, Trueb B. Down-regulated proteins of mesenchymal tumor cells. Exp Cell Res. 1998;239(1):161-8. doi:10.1006/excr.1997.3896.

22. Shields JM, Rogers-Graham K, Der CJ. Loss of transgelin in breast and colon tumors and in RIE-1 cells by Ras deregulation of gene expression through Raf-independent pathways. J Biol Chem. 2002;277(12):9790-9. doi:10.1074/ jbc.M110086200.

23. Prasad PD, Stanton JA, Assinder SJ. Expression of the actin-associated protein transgelin (SM22) is decreased in prostate cancer. Cell Tissue Res. 2010;339(2):337-47. doi:10.1007/s00441-009-0902-y.

24. Wulfkuhle JD, Sgroi DC, Krutzsch H, McLean K, McGarvey K, Knowlton M, et al. Proteomics of human breast ductal carcinoma in situ. Cancer Res. 2002;62(22):6740-9.
25. Thweatt R, Lumpkin Jr CK, Goldstein S. A novel gene encoding a smooth muscle protein is overexpressed in senescent human fibroblasts. Biochem Biophys Res Commun. 1992;187(1):1-7.

26. Gonos ES, Derventzi A, Kveiborg M, Agiostratidou G, Kassem M, Clark BF, et al. Cloning and identification of genes that associate with mammalian replicative senescence. Exp Cell Res. 1998;240(1):66-74. doi:10.1006/ excr.1998.3948.

27. Dumont $\mathrm{P}$, Burton $\mathrm{M}$, Chen QM, Gonos ES, Frippiat C, Mazarati JB, et al. Induction of replicative senescence biomarkers by sublethal oxidative stresses in normal human fibroblast. Free Radic Biol Med. 2000;28(3):361-73.

28. Marshall CB, Krofft RD, Blonski MJ, Kowalewska J, Logar CM, Pippin JW, et al. Role of smooth muscle protein SM22alpha in glomerular epithelial cell injury. Am J Physiol Renal Physiol. 2011;300(4):F1026-42. doi:10.1152/ ajprenal.00187.2010.

29. Zhang ZW, Yang ZM, Zheng YC, Chen ZD. Transgelin induces apoptosis of human prostate LNCaP cells through its interaction with p53. Asian J Androl. 2010;12(2):186-95. doi:10.1038/aja.2009.76.

30. Nair RR, Solway J, Boyd DD. Expression cloning identifies transgelin (SM22) as a novel repressor of 92-kDa type IV collagenase (MMP-9) expression. J Biol Chem. 2006;281(36):26424-36. doi:10.1074/ jbc.M602703200.

31. Kalhori $\mathrm{V}$, Tornquist K. MMP2 and MMP9 participate in S1P-induced invasion of follicular ML-1 thyroid cancer cells. Mol Cell Endocrinol. 2015;404:113-22. doi:10.1016/j.mce.2015.01.037

32. Yeo M, Park HJ, Kim DK, Kim YB, Cheong JY, Lee KJ, et al. Loss of SM22 is a characteristic signature of colon carcinogenesis and its restoration suppresses colon tumorigenicity in vivo and in vitro. Cancer. 2010;116(11):2581-9. doi:10.1002/cncr.25003.

33. Li N, Zhang J, Liang $Y$, Shao J, Peng F, Sun M, et al. A controversial tumor marker: is SM22 a proper biomarker for gastric cancer cells? J Proteome Res. 2007;6(8):3304-12. doi:10.1021/pr0702363.

34. Lin Y, Buckhaults PJ, Lee JR, Xiong H, Farrell C, Podolsky RH, et al. Association of the actin-binding protein transgelin with lymph node metastasis in human colorectal cancer. Neoplasia. 2009;11(9):864-73.

35. da Huang W, Sherman BT, Lempicki RA. Systematic and integrative analysis of large gene lists using DAVID bioinformatics resources. Nat Protoc. 2009:4(1):44-57. doi:10.1038/nprot.2008.211.

36. da Huang W, Sherman BT, Lempicki RA. Bioinformatics enrichment tools: paths toward the comprehensive functional analysis of large gene lists. Nucleic Acids Res. 2009;37(1):1-13. doi:10.1093/nar/gkn923.

37. Dedeurwaerder S, Desmedt C, Calonne E, Singhal SK, Haibe-Kains B, Defrance M, et al. DNA methylation profiling reveals a predominant immune component in breast cancers. EMBO Mol Med. 2011;3(12):726-41. doi:10.1002/ emmm.201100801.

38. Rhodes DR, Yu J, Shanker K, Deshpande N, Varambally R, Ghosh D, et al. ONCOMINE: a cancer microarray database and integrated data-mining platform. Neoplasia. 2004;6(1):1-6.

39. Yamamura H, Masuda H, Ikeda W, Tokuyama T, Takagi M, Shibata N, et al. Structure and expression of the human SM22alpha gene, assignment of the gene to chromosome 11, and repression of the promoter activity by cytosine DNA methylation. J Biochem. 1997;122(1):157-67.

40. O'Leary P, Penny SA, Dolan RT, Kelly CM, Madden SF, Rexhepaj E, et al. Systematic antibody generation and validation via tissue microarray technology leading to identification of a novel protein prognostic panel in breast cancer. BMC Cancer. 2013;13:175. doi:10.1186/1471-2407-13-175.

41. Fackler MJ, Umbricht CB, Williams D, Argani P, Cruz LA, Merino VF, et al. Genome-wide methylation analysis identifies genes specific to breast cancer hormone receptor status and risk of recurrence. Cancer Res. 2011;71(19):6195-207. doi:10.1158/0008-5472.CAN-11-1630.

42. Network CGA. Comprehensive molecular portraits of human breast tumours. Nature. 2012;490(7418):61-70. doi:10.1038/nature11412.

43. Gyorffy B, Lanczky A, Eklund AC, Denkert C, Budczies J, Li Q, et al. An online survival analysis tool to rapidly assess the effect of 22,277 genes on breast cancer prognosis using microarray data of 1,809 patients. Breast Cancer Res Treat. 2010;123(3):725-31. doi:10.1007/ s10549-009-0674-9.

44. Yao TT, Mo SM, Liu LY, Lu HW, Huang ML, Lin ZQ. 5-Aza-2'-deoxycytidine may influence the proliferation and apoptosis of cervical cancer cells via demethylation in a dose- and time-dependent manner. Genet Mol Res. 2013;12(1):312-8. doi:10.4238/2013.February.4.5. 
45. Gomyo Y, Sasaki J, Branch C, Roth JA, Mukhopadhyay T. 5-aza-2'-deoxycytidine upregulates caspase-9 expression cooperating with p53-induced apoptosis in human lung cancer cells. Oncogene. 2004;23(40):6779-87. doi:10.1038/ sj.onc. 1207381

46. Zhu WG, Hileman T, Ke Y, Wang P, Lu S, Duan W, et al. 5-aza-2'-deoxycytidine activates the p53/p21Waf1/Cip1 pathway to inhibit cell proliferation. J Biol Chem. 2004;279(15):15161-6. doi:10.1074/jbc.M311703200.

47. Hackanson B, Daskalakis M. Decitabine. Recent Results Cancer Res. 2014;201:269-97. doi:10.1007/978-3-642-54490-3_18.

48. Hirasawa Y, Arai M, Imazeki F, Tada M, Mikata R, Fukai K, et al. Methylation status of genes upregulated by demethylating agent 5-aza-2'-deoxycytidine in hepatocellular carcinoma. Oncology. 2006;71(1-2):77-85. doi:10.1159/000100475.

49. Zhao L, Wang H, Deng YJ, Wang S, Liu C, Jin H, et al. Transgelin as a suppressor is associated with poor prognosis in colorectal carcinoma patients. Mod Pathol. 2009;22(6):786-96. doi:10.1038/ modpathol.2009.29.

50. Murria R, Palanca S, de Juan I, Egoavil C, Alenda C, Garcia-Casado Z, et al. Methylation of tumor suppressor genes is related with copy number aberrations in breast cancer. Am J Cancer Res. 2015;5(1):375-85.

51. Gormally E, Caboux E, Vineis P, Hainaut P. Circulating free DNA in plasma or serum as biomarker of carcinogenesis: practical aspects and biological significance. Mutat Res. 2007;635(2-3):105-17. doi:10.1016/ j.mrrev.2006.11.002.

52. Jeronimo C, Costa I, Martins MC, Monteiro P, Lisboa S, Palmeira C, et al. Detection of gene promoter hypermethylation in fine needle washings from breast lesions. Clin Cancer Res. 2003;9(9):3413-7.

53. Krassenstein R, Sauter E, Dulaimi E, Battagli C, Ehya H, Klein-Szanto A, et al. Detection of breast cancer in nipple aspirate fluid by $\mathrm{CpG}$ island hypermethylation. Clin Cancer Res. 2004;10(1 Pt 1):28-32.

54. Antill YC, Mitchell G, Johnson SA, Devereux L, Milner A, Di lulio J, et al. Gene methylation in breast ductal fluid from BRCA1 and BRCA2 mutation carriers. Cancer Epidemiol Biomarkers Prev. 2010;19(1):265-74. doi:10.1158/10559965.EPI-09-0359.

55. Van De Voorde L, Speeckaert R, Van Gestel D, Bracke M, De Neve W, Delanghe J, et al. DNA methylation-based biomarkers in serum of patients with breast cancer. Mutat Res. 2012;751(2):304-25. doi:10.1016/.j.mrrev.2012.06.001.

56. Shukla S, Mirza S, Sharma G, Parshad R, Gupta SD, Ralhan R. Detection of RASSF1A and RARbeta hypermethylation in serum DNA from breast cancer patients. Epigenetics. 2006;1(2):88-93.

57. Kim JH, Shin MH, Kweon SS, Park MH, Yoon JH, Lee JS, et al. Evaluation of promoter hypermethylation detection in serum as a diagnostic tool for breast carcinoma in Korean women. Gynecol Oncol. 2010;118(2):176-81. doi:10.1016/j.ygyno.2010.04.016.

58. Naito S, Pippin JW, Shankland SJ. The glomerular parietal epithelial cell's responses are influenced by SM22 alpha levels. BMC Nephrol. 2014;15:174. doi:10.1186/1471-2369-15-174.

59. Groger CJ, Grubinger M, Waldhor T, Vierlinger K, Mikulits W. Meta-analysis of gene expression signatures defining the epithelial to mesenchymal transition during cancer progression. PLoS One. 2012;7(12), e51136. doi:10.1371/journal.pone.0051136.

60. Thompson O, Moghraby JS, Ayscough KR, Winder SJ. Depletion of the actin bundling protein SM22/transgelin increases actin dynamics and enhances the tumourigenic phenotypes of cells. BMC Cell Biol. 2012;13:1. doi:10.1186/ 1471-2121-13-1.

61. Pang J, Liu WP, Liu XP, Li LY, Fang YQ, Sun QP, et al. Profiling protein markers associated with lymph node metastasis in prostate cancer by DIGEbased proteomics analysis. J Proteome Res. 2010;9(1):216-26. doi:10.1021/ pr900953s.

62. Park GH, Lee SJ, Yim H, Han JH, Kim HJ, Sohn YB, et al. TAGLN expression is upregulated in NF1-associated malignant peripheral nerve sheath tumors by hypomethylation in its promoter and subpromoter regions. Oncol Rep. 2014;32(4):1347-54. doi:10.3892/or.2014.3379.

63. Mikuriya K, Kuramitsu Y, Ryozawa S, Fujimoto M, Mori S, Oka M, et al. Expression of glycolytic enzymes is increased in pancreatic cancerous tissues as evidenced by proteomic profiling by two-dimensional electrophoresis and liquid chromatography-mass spectrometry/mass spectrometry. Int J Oncol. 2007;30(4):849-55.

64. Klade CS, Voss T, Krystek E, Ahorn H, Zatloukal K, Pummer K, et al. Identification of tumor antigens in renal cell carcinoma by serological proteome analysis. Proteomics. 2001;1(7):890-8. doi:10.1002/16159861(200107)1:7<890::AID-PROT890>3.0.CO;2-Z
65. Rho JH, Roehrl MH, Wang JY. Tissue proteomics reveals differential and compartment-specific expression of the homologs transgelin and transgelin-2 in lung adenocarcinoma and its stroma. J Proteome Res. 2009;8(12):5610-8. doi:10.1021/pr900705r.

66. Assinder SJ, Stanton JA, Prasad PD. Transgelin: an actin-binding protein and tumour suppressor. Int J Biochem Cell Biol. 2009;41(3):482-6. doi:10.1016/ j.biocel.2008.02.011.

67. Yang Z, Chang YJ, Miyamoto H, Ni J, Niu Y, Chen Z, et al. Transgelin functions as a suppressor via inhibition of ARA54-enhanced androgen receptor transactivation and prostate cancer cell growth. Mol Endocrinol. 2007;21(2):343-58. doi:10.1210/me.2006-0104.

68. Ryu JW, Kim HJ, Lee YS, Myong NH, Hwang CH, Lee GS, et al. The proteomics approach to find biomarkers in gastric cancer. J Korean Med Sci. 2003;18(4):505-9.

69. Yu B, Chen X, Li J, Qu Y, Su L, Peng Y, et al. Stromal fibroblasts in the microenvironment of gastric carcinomas promote tumor metastasis via upregulating TAGLN expression. BMC Cell Biol. 2013;14:17. doi:10.1186/14712121-14-17.

70. Shapland C, Hsuan JJ, Totty NF, Lawson D. Purification and properties of transgelin: a transformation and shape change sensitive actin-gelling protein. J Cell Biol. 1993;121(5):1065-73.

71. Hall A. The cytoskeleton and cancer. Cancer Metastasis Rev. 2009;28(1-2):5-14. doi:10.1007/s10555-008-9166-3.

72. Shen J, Yang M, Ju D, Jiang H, Zheng JP, Xu Z, et al. Disruption of SM22 promotes inflammation after artery injury via nuclear factor kappaB activation. Circ Res. 2010;106(8):1351-62. doi:10.1161/ CIRCRESAHA.109.213900.

73. Gimona M, Kaverina I, Resch GP, Vignal E, Burgstaller G. Calponin repeats regulate actin filament stability and formation of podosomes in smooth muscle cells. Mol Biol Cell. 2003;14(6):2482-91. doi:10.1091/mbc.E02-11-0743.

74. Gourlay CW, Carpp LN, Timpson P, Winder SJ, Ayscough KR. A role for the actin cytoskeleton in cell death and aging in yeast. J Cell Biol. 2004;164(6):803-9. doi:10.1083/jcb.200310148.

75. Kato Y, Salumbides BC, Wang XF, Qian DZ, Williams S, Wei Y, et al. Antitumor effect of the histone deacetylase inhibitor LAQ824 in combination with 13-cisretinoic acid in human malignant melanoma. Mol Cancer Ther. 2007;6(1):70-81. doi:10.1158/1535-7163.MCT-06-0125.

76. Zhang R, Zhou L, Li Q, Liu J, Yao W, Wan H. Up-regulation of two actin-associated proteins prompts pulmonary artery smooth muscle cell migration under hypoxia. Am J Respir Cell Mol Biol. 2009;41(4):467-75. doi:10.1165/rcmb.2008-03330C.

77. Kaverina I, Stradal TE, Gimona M. Podosome formation in cultured A7r5 vascular smooth muscle cells requires Arp2/3-dependent de-novo actin polymerization at discrete microdomains. J Cell Sci. 2003;116(Pt 24):4915-24. doi:10.1242/jcs.00818.

78. Yu H, Konigshoff M, Jayachandran A, Handley D, Seeger W, Kaminski N, et al. Transgelin is a direct target of TGF-beta/Smad3-dependent epithelial cell migration in lung fibrosis. FASEB J. 2008;22(6):1778-89. doi:10.1096/fj.07-083857.

79. Chunhua L, Donglan L, Xiuqiong F, Lihua Z, Qin F, Yawei L, et al. Apigenin up-regulates transgelin and inhibits invasion and migration of colorectal cancer through decreased phosphorylation of AKT. J Nutr Biochem. 2013;24(10):1766-75. doi:10.1016/j.jnutbio.2013.03.006.

80. Ye J, Coulouris G, Zaretskaya I, Cutcutache I, Rozen S, Madden TL. PrimerBLAST: a tool to design target-specific primers for polymerase chain reaction. BMC Bioinformatics. 2012;13:134. doi:10.1186/1471-2105-13-134.

81. Gur-Dedeoglu B, Konu O, Bozkurt B, Ergul G, Seckin S, Yulug IG. Identification of endogenous reference genes for qRT-PCR analysis in normal matched breast tumor tissues. Oncol Res. 2009;17(8):353-65.

82. Winer J, Jung CK, Shackel I, Williams PM. Development and validation of real-time quantitative reverse transcriptase-polymerase chain reaction for monitoring gene expression in cardiac myocytes in vitro. Anal Biochem. 1999:270(1):41-9. doi:10.1006/abio.1999.4085.

83. Kumaki Y, Oda M, Okano M. QUMA: quantification tool for methylation analysis. Nucleic Acids Res. 2008;36(Web Server issue):W170-5. doi:10.1093/ nar/gkn294.

84. McCarty Jr KS, Szabo E, Flowers JL, Cox EB, Leight GS, Miller L, et al. Use of a monoclonal anti-estrogen receptor antibody in the immunohistochemical evaluation of human tumors. Cancer Res. 1986;46(8):4244s-8s.

85. Mihaly Z, Kormos M, Lanczky A, Dank M, Budczies J, Szasz MA, et al. A metaanalysis of gene expression-based biomarkers predicting outcome after tamoxifen treatment in breast cancer. Breast Cancer Res Treat. 2013;140(2):219-32. doi:10.1007/s10549-013-2622-y. 